BULLETIN Bulletin hispanique

HispaniQuE Université Michel de Montaigne Bordeaux

119-1 | 2017

Autorité et pouvoir dans le théâtre du Siècle d'Or

\title{
Modos de autoridad y poder femeninos en Tirso de Molina y Bances Candamo
}

\section{Blanca Oteiza}

\section{(2) OpenEdition}

1 Journals

\section{Edición electrónica}

URL: http://journals.openedition.org/bulletinhispanique/4898

DOI: 10.4000/bulletinhispanique.4898

ISBN: 979-10-300-0142-6

ISSN: 1775-3821

Editor

Presses universitaires de Bordeaux

Edición impresa

Fecha de publicación: 15 junio 2017

Paginación: 231-244

ISBN: 979-10-300-0141-9

ISSN: 0007-4640

\section{Referencia electrónica}

Blanca Oteiza, " Modos de autoridad y poder femeninos en Tirso de Molina y Bances Candamo », Bulletin hispanique [En línea], 119-1 | 2017, Publicado el 15 junio 2020, consultado el 12 septiembre 2020. URL : http://journals.openedition.org/bulletinhispanique/4898 ; DOI : https://doi.org/10.4000/ bulletinhispanique.4898 


\title{
Modos de autoridad y poder femeninos en Tirso de Molina y Bances Candamo ${ }^{1}$
}

\author{
Blanca Oteiza \\ GRISO-Universidad de Navarra
}

María de Molina et Christine de Suède, deux femmes singulières dans l'histoire, offrent deux cas intéressants d'autorité et de pouvoir féminins dans les comedias du Siècle d'Or : La prudencia en la mujer de Tirso de Molina, et Quién es quien premia al amor de Bances Candamo.

Mots-clés: histoire, poésie, femme, monarchie, Tirso de Molina.

María de Molina y Cristina de Suecia son dos singulares mujeres de la historia, que representan dos interesantes casos de autoridad y poder femeninos en las comedias del Siglo de Oro La prudencia en la mujer de Tirso de Molina y Quién es quien premia al amor de Bances.

Palabras clave: historia, poesía, mujer, monarquía, Tirso de Molina.

Maria de Molina and Cristina of Sweden are two outstanding women in history, representing two interesting examples of authority and female power in two plays of the Golden Age: "La prudencia en la mujer" by Tirso de Molina and "Quién es quien premia al amor" by Bances.

Keywords: history, poetry, woman, monarchy, Tirso de Molina.

1. Esta publicación se enmarca en el Proyecto de Investigación Edición crítica del teatro completo de Tirso de Molina. Cuarta fase (FFI2013-48549-P), subvencionado por el Ministerio de Economía y Competitividad de España. 
$\mathrm{M}$ aría de Molina y Cristina de Suecia resultan tan distantes en el tiempo y sus circunstancias como sus autores, Tirso y Bances Candamo², y a la vez mujeres tan singulares de la historia, que han merecido ser llevadas al teatro áureo respectivamente en La prudencia en la mujer de Tirso (redactada entre 1622-1623), y Quién es quien premia al amor, de Bances, escrita probablemente en $1693^{3}$, personalizando dos relevantes casos de autoridad y poder femeninos ${ }^{4}$.

Ambas reinas, de la historia antigua de Castilla, María de Molina, y de la historia contemporánea europea, Cristina de Suecia, protagonizan sendas comedias en las que junto al atractivo de la propia historia, de sus biografías, lo que interesa especialmente es la construcción de la Poesía gracias al ingenio del dramaturgo: es decir, cómo selecciona la materia histórica, la organiza, combina, altera y manipula, para darle forma dramática.

\section{La prudencia en la mujer, de Tirso}

En el caso de Tirso, su teatro tiene una interesante representación de reinas, protagonistas o secundarias 5 : de la historia de Castilla, Isabel la Católica en Antona García; la celosa reina Isabel, esposa de Juan II, en Doña Beatriz de Silva; de la historia bíblica, la malvada agresora Jezabel en La mujer que manda

2. Si bien ambos dramaturgos comparten, con las salvedades y precisiones debidas, algunos aspectos: manifiestan sus reflexiones sobre su concepción del teatro, sostienen la primacía de la Poesía frente a la Historia; no ocultan el orgullo e importancia de su condición de ingenios cómicos; defienden un componente provechoso del teatro, etc. Tirso expondrá sus ideas en la miscelánea Cigarrales de Toledo, en sus comedias, especialmente El vergonzoso en palacio y $\mathrm{La}$ fingida Arcadia; en los paratextos de las tercera, cuarta y quinta partes de sus comedias, etc. Bances, por su parte, las reúne en Teatro de los teatros.

3. Sigo la edición de Gregorio Torres Nebrera para la comedia de Tirso, La prudencia en la mujer, Madrid, Cátedra, 2010, y para la de Bances Quién es quien premia al amor, la de Blanca Oteiza, publicada en Francisco Antonio Bances Candamo, Poesías cómicas, I, 1, editora general Blanca Oteiza, Madrid, Iberoamericana, 2014, pp. 241-436, donde se pueden ampliar y completar los detalles de este trabajo. El interés por ambas reinas persiste en el tiempo: en 1933 Greta Garbo protagoniza Queen Christina, de Rouben Mamoulian (una fabulación romántica de sus amores con un diplomático español); y María de Molina ha sido llevada al teatro en varias ocasiones, ver para su recepción Torres Nebrera, ed. cit., pp. 45-55; además se le dedica en 1995 un documental en la serie Mujeres de la historia de RTVE con el apodo de la reina sabia, y en 2004 Almudena de Arteaga, la hace protagonista de Tres coronas medievales, premio de novela histórica "Alfonso X el Sabio».

4. Para los conceptos de autoridad y poder, que centran una de las líneas de investigación del GRISO, dirigida por Ignacio Arellano (www.unav.edu/evento/autoridad-poder/), ver José Enrique Duarte, "Autoridad(es) y poder(es) en Monseñor Quijote de Graham Greene», en Alpha, 43, 2016, pp. 245-256.

5. Un completo catálogo de reinas del teatro áureo en Ana Zúniga, Mujer y poder en el teatro español del Siglo de Oro: la figura de la reina, Kassel, Reichenberger, 2015. Para la figura de Isabel la Católica en el teatro de Tirso, ver María Y. Caba, Isabel la Católica en la producción teatral española del siglo XVII, Woodbridge, Tamesis, 2008, pp. 83-131. 
en casa; de la historia legendaria, la emperatriz Irene en La república al revés, o de la fabulación de Tirso, las amenazadas reinas bohemias de La ventura con el nombre... Pero es María de Molina, que vivió entre los siglos XIII y XIV (12601321), la protagonista de la considerada por algunos la mejor comedia histórica de Tirso, La prudencia en la mujer.

Casada con Sancho IV que al morir (1295) dejó heredero a su hijo Fernando (futuro Fernando IV) de nueve años, fue regente hasta que cumplió los 16 años, edad en que es coronado rey ${ }^{7}$.

Los documentos contemporáneos recogen las difíciles circunstancias de su regencia, insistiendo en su condición de mujer. Así fray Hernando del Castillo en la Historia de Santo Domingo y de su Orden, de 1612 cuenta que

Casada trece ańos y veintiséis viuda, y todos ellos fueron un continuo martirio, sin tener una hora que no fuese desasosiegos, guerras, levantamientos de pueblos, traiciones, pleitos; y esto en vida de su marido. Muerto él y quedando por tutora de su hijo, todo fue para ella una cruz, con don Enrique, con el infante don Juan, con los Cerdas, [...] con Francia, Aragón, Portugal, Navarra y Granada: que verdaderamente parecía que la tierra se levantaba contra ella. [...] Los caminos que anduvo, los trabajos, los cuidados, las vistas con los reyes y con sus enemigos, los tratos, los medios, las paces que asentó con unos y con otros, parece imposible a una mujer [...] Alcanzaba de Dios tanto favor cuanto era menester para sufrir los agravios de sus vasallos y los de su hijo con paciencia cristiana, tener prudencia y discreción para gobernarse [...]. Vio por sus ojos compromisos, partijas, sentencias y divisiones de estos reinos, embustes, invenciones y falsedades y otras mil cosas, bastantes para descomponer grandes varones con pecho de acero, cuanto más a una mujer sola y contra todos. ${ }^{8}$

Y Tirso, centrándose especialmente en estos problemas internos del reino, lo que va a dramatizar es cómo logra sortear esta mujer dichos inconvenientes gracias a su prudencia.

Una prudencia, entendida no con el sentido que se ha impuesto en la actualidad de actuar con precaución para evitar posibles daños, sino con el de inteligencia, sagacidad, y astucia..., es decir el relacionado con la virtud cardinal de la Prudencia, llamada «auriga virtutum» porque «conduce las otras virtudes, indicándoles regla y medida», y relacionada con la sabiduría ${ }^{9}$, y así el

6. Torres Nebrera la califica de «la mejor» de los ocho dramas históricos de Tirso (ver ed. cit. pp. 13, 27 y 39-40).

7. Para el trasfondo histórico remito al excelente estudio de Torres Nebrera, ed. cit., pp. 2738.

8. Torres Nebrera, ed. cit. p. 37.

9. Ver Luis Martínez Fernández, Diccionario del Catecismo de la Iglesia Católica, Madrid, Biblioteca de Autores Cristianos, 1995, p. 254 y Pedro Canisius, Doctrina cristiana, ed. Rafael Zafra, Islas Baleares, José J. de Olañeta editor, 2014, pp. 164-165; y para su percepción en el Siglo de Oro, Ángel Pérez Martínez, El buen juicio en el Quijote. Un estudio desde la idea de la prudencia en los Siglos de Oro, Valencia, Pre-textos, 2005 y Aurora Egido, Las caras de la prudencia y Baltasar de Gracián, Madrid, Castalia (NBEC), 2000, especialmente pp. 91-97. 
hombre prudente, es el «sabio y reportado, que pesa todas las cosas con mucho acuerdo" ${ }^{10}$.

Esta prudencia, que no es atribución de Tirso, es la imagen sobre la que construye el personaje, y procede de la historia de su tiempo, pues como señala Torres Nebrera en la Crónica de Fernando IV de Jofré de Loaysa del siglo XIII se la describe como "prudens domina» ("tanquam prudens multum et circunspecta domina» $)^{11}$. Pero esta prudencia asociada a la mujer supone en la época una contradicción ${ }^{12}$ por ser términos antagónicos al igual que lo eran la hermosura y discreción, por lo que cuando se unen en una mujer son ponderación. Y en Tirso todo es ponderación de la reina María.

El Mercedario sigue muy de cerca la historia ${ }^{13}$ con las alteraciones poéticas debidas, que ahora no importan, porque interesa cómo construye el personaje dramático a partir del histórico. Para ello esta prudencia se acompañará de otras cualidades que la convierten en un dechado de virtudes como mujer: viuda, madre, reina y por supuesto cristiana ejemplar. Y de ello dará prueba a través de sus hechos y palabras, pero también de su imagen, en los continuados ataques a la regencia y al niño-rey, por parte de sus enemigos, que la ponen a prueba con una intensidad proporcional a la prudencia con que los resolverá.

Su condición de viuda es la primera en ser atacada. Los dos cuñados traidores, Enrique y Juan, junto con don Diego quieren casarse con ella y esgrimen argumentos en favor de cada uno. Seguidamente aparece por vez primera la reina de manera relevante, «de viuda», y como explica ella misma de negro y con telas bastas, sin galas mundanas, para defender esta viudedad, y su integridad moral, absoluta fidelidad y castidad. Este rechazo recibe la primera amenaza de su cuñado don Juan por hablar «arrogante y sin prudencia». Así comienza la obra, con la tensión dramática que manda la convención, marcando el tono en que transcurrirá su regencia y la comedia.

Malograda la estrategia del matrimonio, el siguiente ataque por parte de los traidores (los infantes Enrique y Juan) se dirige a su condición de reina con la toma de Toledo, que posteriormente recuperarán los aliados de María apresando a los dos infantes sediciosos, iniciando una serie de resoluciones desconcertantes: la reina sorprende mostrando piedad y generosidad con los

10. Sebastián de Covarrubias, Tesoro de la lengua castellana, eds. Ignacio Arellano y Rafael Zafra, Madrid, Iberoamericana, 2006.

11. Torres Nebrera, ed. cit., p. 38.

12. Oxímoron en el que insiste Torres Nebrera, ed. cit., pp. 38, 65.

13. El infante don Juan, hermano de Sancho, y cuñado de María, reina regente, y tío del niño-rey, con sus nobles partidarios emprendió diversas acciones militares para derrocarlo y hacerse con el reino, hasta que finalmente desistió y le reconoció obediencia; sí consta que acusaron ante el rey a la reina de malversación de cuentas públicas durante la regencia; que desviaron la atención del rey y del gobierno con cacerías y que lo malquistaron con su madre. En cuanto al médico judío, y sin olvidar que la mayoría de los reyes los tuvieron a su servicio, se han propuesto algunos modelos históricos y literarios en los que se pudo basar Tirso (ver Torres Nebrera, ed. cit., pp. 69-70, 105). 
vencidos traidores, y en vez de su ejecución les otorga el perdón y la concesión de bienes territoriales. YTirso consciente de este extraño comportamiento (más bien imprudente diríamos ${ }^{14}$ ) pone en boca de la reina la explicación, que estará apoyada y potenciada en escena precisamente con su imagen soberana, cuando:

Sobre un trono se aparece la reina en pie, coronada, con peto y espaldar, echados los cabellos, y una espada desnuda en la mano

diciendo:

\author{
La reina doña María \\ castiga de aquesta suerte \\ delitos dignos de muerte. (vv. 1003-1005)
}

Esto hace que los infantes traidores se rindan ante ella y con su vasallaje, momentáneo como se verá, termina el primer acto.

Pero María es también madre y durante los dos primeros actos se ocupa de proteger a su hijo y defender su trono ${ }^{15}$. Esta faceta se desarrolla en el episodio en que don Juan, que sigue empeñado en apoderarse del trono, idea el asesinato del niño mediante un médico judío que intentará envenenarlo. Y la escena se concibe con una imagen de la reina-madre, la de su retrato, que va a funcionar con el mismo sentido protector de la Virgen madre ${ }^{16}$, al caer e impedir que el médico entre en la habitación del niño. Las acotaciones van graduando la acción que la reina dirige con habilidad hasta obligarlo a beber el veneno: Saca el judio un vaso de plata. Quiere entrar [en la habitación del niño] y esté sobre la puerta el retrato de la reina, de viuda. Esto lo detiene, impresionado por la «majestad» de su imagen, pero insiste: Quiere entrar, cae el retrato, y tápale la puerta. Lo intenta por otro lado: Quiere entrar por la otra puerta, y sale la reina, $y$ detiénele y él se turba. Quiere derramarla [la copa], y tiénele la reina, que le obligará a tomar el veneno, y Cae muerto dentro, no sin antes haber logrado que confiese que ha sido don Juan el instigador del crimen.

14. Para Torres Nebrera «en la generosidad de su gesto hay desprecio o minusvaloración del oponente, y en ningún caso sombra de debilidad» (ed. cit., p. 68). Para Ignacio Arellano, «la prudencia no se desprende de la misma acción, sino del discurso verbal, de la caracterización directa y del empeño previo del dramaturgo» («La incoherente sacralización de una reina: $L a$ prudencia en la mujer, de Tirso, y los riesgos del prejuicio", en La santa Juana y el mundo de lo sagrado, ed. Blanca Oteiza, Madrid-Pamplona-New York, Instituto de Estudios Tirsianos-IDEA, 2016, pp. 121-141, cita en p. 135.

15. Ver Frederick De Armas, «La prudencia en la mujer de Tirso de Molina: monumento a una madre ideal», en La madre en el teatro clásico español. Personaje y referencia, ed. Luciano García Lorenzo, Madrid, Fundamentos, 2012, pp. 103-117.

16. Ver Christopher Weimar, «Los retratos salvadores en dos comedias de Tirso de Molina: "La prudencia en la mujer" y "La firmeza en la hermosura"”, en El sustento de los discretos. La dramaturgia áulica de Tirso de Molina, eds. Eva Galar y Blanca Oteiza, Madrid-Pamplona, Instituto de Estudios Tirsianos, 2003, pp. 149-158, con su bibliografía y Torres Nebrera, ed. cit., pp. 69-70. 
La reacción de María será perdonar al infante, perdón explicado y basado ahora en una cuestión religiosa, la de la oposición secular entre judíos y cristianos, en la que se defiende la supremacía del cristiano, aunque traidor, frente al judío, muy en la línea del antisemitismo que se revela en Tirso ${ }^{17}$, lo que parece ciertamente otra imprudencia, ahora justificada porque en este perdón subyace una estrategia: la maniobra de la reina es lograr que el traidor escriba un texto cifrado que es el reconocimiento de su propia culpabilidad, y que le servirá más adelante para desenmascararle ${ }^{18}$.

Consigue así de nuevo (luego sabremos que sin ninguna sinceridad) el reconocimiento por parte de don Juan de la prudencia que la adorna, en una frase que queda sin terminar: "No tengo lengua, señora, / para ensalzar al presente / la prudencia que en vos...» (v. 1818), es decir el juicio, la sensatez que ahora le viene tan bien.

Pero de nuevo poco va a durar la veracidad de estas palabras, y el siguiente ataque de don Juan contra la reina será intentar romper su imagen mediante falsos testimonios: que exhibe una santidad fingida, es arrogante y ambiciosa, deshonesta y desleal..., acusaciones de las que saldrá triunfadora, también por sus hechos.

Así mientras la reina y su hijo no tienen qué comer, ni cómo pagar a sus soldados, por lo que tiene que vender hasta sus tocas de viuda, sorprende «armada» a los traidores que están conspirando en torno a una mesa opípara, situación que aprovecha para exigir a don Juan que confiese ser el inductor del envenenamiento del rey, y después confinarlo en sus tierras, a la par que perdona a los demás a cambio de sus castillos, lo que hace que don Diego cierre el acto aludiendo una vez más a su prudencia:

\author{
No llegue el tiempo a ofender \\ tal valor, pues vengo a ver \\ en nuestro siglo, apacible, \\ lo que parece imposible: \\ que es prudencia en la mujer. (vv. 2288-2292)
}

En la tercera jornada, el niño ya es monarca y María empobrecida se va a retirar a una de las pocas aldeas que le quedan, aprovechando la despedida para completar su función de madre y reina con una serie de consejos y avisos de buen gobierno.

Pero don Juan, fuera ya de su reclusión, prepara el último ataque contra María en sus facetas de viuda y de reina, desacreditándola ante su hijo, que enseguida muestra su debilidad y condición de mal gobernante. Como viuda, la difamará

17. Ver para el antisemitismo de Tirso, Ignacio Arellano, «Judíos y antisemitismo en dos comedias de Tirso», en Felipe Pedraza, Rafael González Cañal y Elena Marcello (eds.), Judaísmo y criptojudaísmo en la comedia española, Cuenca, Ediciones de la Universidad de Castilla-La Mancha, 2014, pp. 39-58.

18. Ver Torres Nebrera, ed. cit., pp. 71-72. 
atribuyéndole relaciones ilícitas con su vasallo don Juan de Carvajal (vv. 27582769; 2870-2877), y después pidiéndola en matrimonio para destronar a su propio hijo (vv. 3382-3388), y como reina la acusará «de cohecho y apropiación indebida de fondos de la corona» ${ }^{19}$. Pero nuevamente María saldrá con éxito, al defender su buen gobierno y su buen nombre, acusando con pruebas al traidor ante el rey, siguiendo de cerca la historia, pues efectivamente, como apunta Torres Nebrera, María tuvo que rendir cuentas a su propio hijo en las Cortes de Medina, donde demostró que no solo no había malgastado el dinero sino que la corona estaba en deuda con ella porque había puesto al servicio del reino su propio patrimonio ${ }^{20}$.

Y la reacción de María ante estas acusaciones una vez más será la clemencia para don Juan, pero ahora castigándolo con el destierro y repartiendo sus estados y haciendas entre sus víctimas, actitud que elogiará el rey dando fin a la comedia:

\author{
Vuestra Alteza, señora, \\ con su vida ilustre enseña \\ que hay mujeres en España \\ con valor y con prudencia. (vv. 3673-3675)
}

De manera que Tirso selecciona de la historia episodios emocionantes, y fabula otros impactantes como el del médico judío, en los que esta mujerreina en un entorno hostil masculino tiene que dedicar su valor e inteligencia (prudencia) a desenmascar sucesivamente al infante traidor para defender la corona y su honor de viuda y reina, haciendo posible el reconocimiento de la prudencia en la mujer, aunque para ello Tirso se encargue repetidamente de justificar y explicar cada una de las reacciones de la reina con el traidor ${ }^{21}$.

\title{
Quién es quien premia al amor, de Bances
}

Haciendo un salto en el tiempo histórico y en el tiempo de escritura, nos situamos en 1654 año en que la reina Cristina de Suecia sacude Europa con su abdicación y conversión al catolicismo.

Se conservan interesantes testimonios en la correspondencia de los diplomáticos y en las noticias de la época (los Avisos de Barrionuevo) que informan sobre la reina, su corte e intenciones así como del proceso, en el que tuvo un papel importante Felipe IV y sus embajadores, el conde de Rebolledo

19. Torres Nebrera, ed., cit., p. 76.

20. Torres Nebrera, ed. cit., pp. 34-35.

21. «nótese que en esa prudente actitud, reiterada al final de cada acto, se produce una gradación en sus veredictos: le perdona, con dádivas ańadidas, en el primer caso; le manda encarcelar en sus tierras, en el segundo, y le destierra de Castilla y le despoja de las tierras entregadas en un principio» (Torres Nebrera, ed .cit., p. 80). 
en Dinamarca y Antonio Pimentel en Suecia, quienes trabaron estrecha amistad con la reina ${ }^{22}$.

Estaríamos hablando del periodo entre 1652-1654 en el que Pimentel fue embajador en Suecia, hasta la abdicación el 6 de junio de 1654 en favor de su primo Carlos Gustavo con quien no había querido casarse. Son años de intensa actividad diplomática y estrechas relaciones entre la monarquía española y sueca. El interés por la reina y sus asuntos ocupan las cancillerías y los mentideros, que reciben noticias directas de los admirados testigos que conviven con ella en la corte, y que irán configurando su leyenda. Se la describe masculina y sin interés por acicalarse; asombran sus inquietudes y aptitudes intelectuales (sabe diez u once lenguas; tiene memoria prodigiosa), y gusta de fiestas (mascaradas, ballets de trajes antiguos, disfraces...) en las que interviene la propia reina haciendo pareja y distinguiendo a Pimentel... como aquella en la que crea la Orden de la Amaranta, de la que informa el embajador Rebolledo:

Hacíanse en Estocolmo diferentes fiestas y, entre ellas, instituyó la Reina una Orden, que llamó de Amaranta, de la que era ella el gran Maestre y la insignia dos aes de diamantes cruzadas dentro de un círculo de Amaranto, y escrito alrededor dél Dolce ne la memoria, y una banda de color fuego, bordada de las mismas aes y guarnecida de grandes puntas de plata y oro. Uno de los primeros a quien la dio fue a don Antonio Pimentel ${ }^{23}$.

Pero una vez que Cristina de Suecia llega a Roma tras abdicar y convertirse, las relaciones con los españoles se enfrían hasta romperse, por lo que Felipe IV decretará en 1656 que no se represente el auto de Calderón La protestación de la fe que protagonizaba la reina sueca, porque las cosas con esta señora no estaban en el estado que tuvieron al principio, cuya casa y servicio de criados se componía ahora sólo de franceses ${ }^{24}$.

Estos hechos que sucedían a mediados del XVII son retomados por Bances Candamo, dramaturgo oficial de Carlos II, en su comedia Quién es quien premia al amor a finales del siglo (1693) para ser representada ante sus majestades en el palacio real por carnaval.

Y podemos preguntarnos qué papel e interés puede tener Cristina de Suecia cuarenta años más tarde para la corte, y por qué rememorar situaciones incómodas como su favor a los franceses, que supuso el desabrido final de la

22. Ver Carlos Clavería Carlos, «Gustavo Adolfo y Cristina de Suecia, vistos por los españoles de su tiempo", Clavileño, 1952, núm. 17, pp. 11-15, y núm. 18, pp. 17-27; Marqués de VillaUrrutia, Cristina de Suecia, Buenos Aires, Espasa-Calpe, "Colección Austral», 1939 (manejo la ed. de 1962); Miguel Lasso de la Vega, Don Antonio Pimentel de Prado, embajador a Cristina de Suecia (1652-1656), Madrid, s. i., 1941; Rafael González Cañal, «El Conde de Rebolledo y la Reina Cristina de Suecia: una amistad olvidada», Revista Tierras de León, León, 1986, núm. 62, pp. 93-108; Úrsula de Allendesalazar, La reina Cristina de Suecia, Madrid, Marcial Pons, 2009, y la introducción a Quién es quien premia al amor.

23. González Cañal, op. cit., p. 104.

24. Clavería, op. cit., p. 27, nota 48. 
amistad entre Cristina y Pimentel y una percepción muy negativa de la reina sueca entre los españoles ${ }^{25}$.

Por ello el tiempo representado se reduce a los momentos memorables de entendimiento entre ambas monarquías, que están en sincronía con el prestigio de la embajada de Pimentel. De hecho, solo se menciona su abdicación y la conversión queda latente con referencias veladas que el embajador diseminará por la comedia. Esto ha llamado la atención de los críticos, pero se justifica fácilmente desde esta perspectiva, que anula otras intencionalidades políticas relacionadas con la cuestión sucesoria de Carlos II, para la que se postulaban varios pretendientes ${ }^{26}$.

Y es que en mi opinión, la comedia estaría motivada por la concesión del título de marqués de Florida Pimentel al sobrino-yerno de Antonio Pimentel, a quien acompañó en su misión de embajador en Suecia, en premio a sus méritos y a los de su tío, mediante decreto dado en Madrid el 26 de enero de 1693. Es decir que Bances habría escrito esta comedia como homenaje al embajador Pimentel ${ }^{27}$.

Para ello, el poeta, como es habitual en él, se documenta sobre la historia de Suecia, y en la correspondencia diplomática encuentra el material necesario para recrear la vida cotidiana de la corte evocando especialmente sus fiestas y bailes, y para modelar a Cristina en sus facetas de mujer y de reina, según el modelo de gobernante que defiende en su Teatro de los teatros ${ }^{28}$.

Cristina, mujer y reina, aglutina el interés de los cuatro galanes de la comedia: el español Antonio Pimentel por interés político-religioso; el danés duque de Holstein y Carlos Gustavo, su prometido oficial, por razón de Estado, y el conde Federico que, en secreto ama desinteresadamente a la mujer. Situaciones que tratará con éxito, recompensándoles en consonancia: el premio de Federico será acompañar a la reina en su peregrinación a Roma; Carlos es emparejado

25. Ver Ignacio Arellano, «Historia, poesía y cotilleos. Cristina de Suecia en los Avisos de Barrionuevo", Revista de Literatura, en prensa.

26. La reina madre, Mariana de Austria, pugnaba en favor del príncipe José Fernando de Baviera, hijo de su nieta María Antonia de Austria, esposa del elector Maximiliano II Manuel de Baviera, y la esposa del rey, Mariana de Neoburgo, a favor de su sobrino, el archiduque Carlos de Austria, hijo de su hermana mayor, Leonor Magdalena de Palatinado-Neoburgo, y del emperador Leopoldo I. Finalmente fue nombrado heredero José Fernando en 1696, que murió en 1699, por lo que el rey hizo testamento en 1700 a favor de Felipe de Anjou, quien reinará como Felipe V, tras la guerra de sucesión.

27. Ver Blanca Oteiza, «Hipótesis de una escritura: "Quién es quien premia al amor", de Bances», en Ignacio Arellano, Víctor García Ruiz, Carmen Saralegui (eds.), Ars bene docendi. Homenaje al profesor Kurt Spang, Pamplona, Eunsa, 2009, pp. 433-442.

28. Es decir con el decoro y respeto debidos a la figura real, «porque aunque sea del palacio de la China solo por el nombre lleva el poeta gran cuidado en poner decorosa la alusión, venerando por imágines aun las sombras de lo que se puede llamar real» (Francisco A. Bances Candamo, Teatro de los teatros de los pasados y presentes siglos, ed. Duncan W. Moir, London, Tamesis Books, 1970, pp. 34-35). 
con su amada Leonor y recibe la corona del reino; el danés duque de Holstein queda suelto. Pimentel resulta vencedor para su causa, la conversión de la reina. Pero veamos en más detalle estas facetas de Cristina.

Su primera aparición se da en un espacio privado, íntimo, e informal, en el que está con sus damas, y que sirve para apuntar su especial personalidad: cercana y sencilla, regia y natural, vanidosa-arrogante, despreocupada...

se descubre un gabinete de espejos [...] y en él un tocador con todos sus adornos. Va saliendo al son de la música la reina Cristina en brial y con un peinador puesto; todas las damas en traje de Suecia van sacando en azafates los vestidos

\begin{tabular}{ll} 
Madama & $\begin{array}{l}\text { Déjame suelto el cabello, } \\
\text { ondeando libre la espalda, } \\
\text { y en un lazo solo arriba } \\
\text { con descuido airoso ata } \\
\text { de esas derramadas hebras } \\
\text { la riza inundación vaga. } \\
\text { ¡Nueva moda! }\end{array}$ \\
Enrica & \multicolumn{1}{c}{ Como mía, } \\
Madama & $\begin{array}{l}\text { Sí, mas como tuya, airosa } \\
\text { Laura }\end{array}$ \\
Madama & \multicolumn{1}{c}{ Tanto me arrastra } \\
& $\begin{array}{l}\text { de lo marcial la afición } \\
- \text { siendo a estudios inclinada- } \\
\text { que aun al traje se me asoma } \\
\text { esta propensión bizarra, } \\
\text { tan propia de reina. (vv. 147, 247-261) }\end{array}$
\end{tabular}

Su aspecto va a evocar esa despreocupación, la poca inclinación al cuidado de su físico, de la que hablan las crónicas, pero muy matizada: frente a los elaborados tocados de la época se refleja la naturalidad de Cristina en el vestir y adorno, es decir su libertad, no su negación. Por ello un rasgo atribuido a la reina, el varonil, queda anulado en la comedia y su personaje, sin dejar su libertad, se configura desde la feminidad: es decir, sin renunciar como mujer a la belleza y a la vanidad.

La siguiente expresión de su carácter atiende a su capacidad intelectual y a la primacía de la mujer sobre la reina, como se ve en estos versos en los que anticipa veladamente su destino que supondrá renunciar a su condición de reina en favor de la de mujer:

$\begin{array}{ll}\text { Madama } & \text { No solo los que pretenden } \\ \text { mi mano, mas los que alaban } \\ \text { mi discreción o hermosura } \\ \text { y las perfecciones varias } \\ \text { que en mí pintan -ya de ser } \\ \text { en todas ciencias versada, } \\ \text { [y] de poseer once idiomas, [...] }\end{array}$




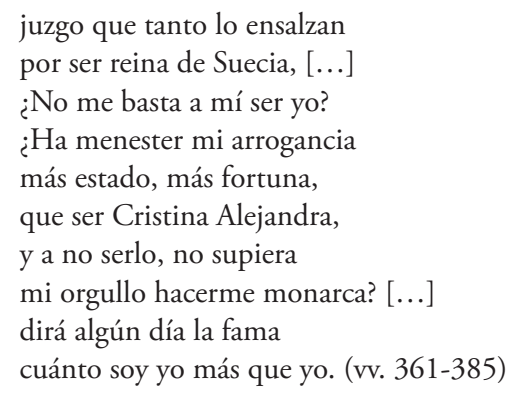

Otro aspecto interesante de esta mujer-reina es el amoroso. Su prometido oficial Carlos Gustavo, con quien no tiene intención de casarse, está enamorado de la danesa Leonor, y Cristina no lo sabe. Sin embargo envidia que Carlos riña por Leonor y cuando los ve juntos el corazón le palpita presagiando esta atracción por lo que se ocultará entre las murtas del jardín para escuchar lo que hablan. El resultado como ella declara es que su vanidad queda resentida al conocer la verdad: Carlos confiesa a Leonor que sirvió a la reina no por inclinación sino por galantería, y para asegurarse el trono, que perdería si la reina se casara con otro. Confidencia que hace reflexionar a la mujer:

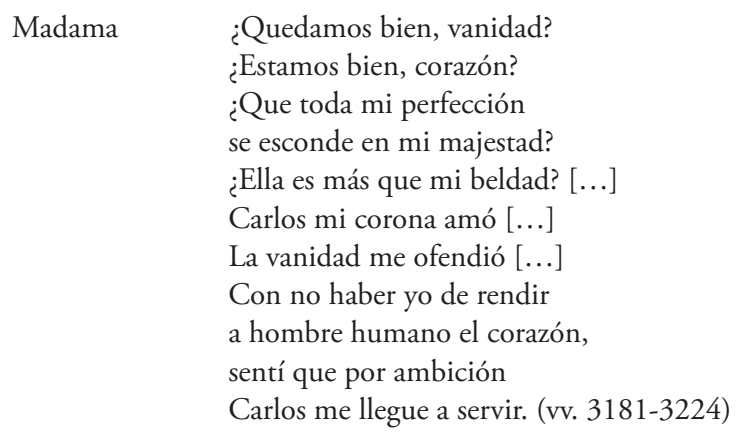

En realidad en las palabras de Carlos Gustavo no hay nada que la pueda sorprender, ella no lo quiere ni tiene intención de casarse con él, pero su confesión ha lastimado su vanidad de mujer: la preferida es otra en su amor.

Ahora bien, en compensación otra revelación, más amable, tendrá a continuación al escuchar en el mismo lugar la conversación de Federico y Laura por la que conocerá que Federico la ama por mujer y no por reina, al contrario que Carlos Gustavo:

\begin{tabular}{ll}
$\begin{array}{l}\text { Federico } \\
\text { Laura }\end{array}$ & Yo, Laura, no amo a la reina. \\
Federico & ¿Pues a quién? \\
& \multicolumn{1}{c}{ Solo a Cristina, } \\
& $\begin{array}{l}\text { que yo por ella la adoro } \\
\text { sin otra prerrogativa } \\
\text { ni otro fin que el de adorarla, } \\
\text { y todo cuanto suspiran }\end{array}$
\end{tabular}


mis ansias premia en exceso

con dejarse ver benigna. (vv. 3269-3276)

Y Cristina manifestará su satisfacción de ser amada como mujer lo que propicia que les avance sus intenciones que en breve confesará dando fin a la comedia:

$\begin{array}{ll}\text { Laura } & \text { ¿Y te precias de querida? } \\ \text { Madama } & \text { Sí, Laura; que no sé que haya } \\ & \text { otro contento en ser linda, } \\ & \text { y la hermosura para algo } \\ & \text { se pule, prende y matiza, } \\ & \text { pues no se esmera en ser bella } \\ & \text { para ser aborrecida. [...] } \\ & \text { Yo estoy, Laura, yo estoy conde, } \\ & \text { en resolución muy fija } \\ & \text { de peregrinar la Europa } \\ & \text { por si mi orgullo averigua } \\ & \text { cuánto más que por mi reino } \\ & \text { me veneran por mí misma. (vv. 3328-3360) }\end{array}$

Pero Cristina es también reina y actúa y procede como tal, transfiriendo su suficiencia de mujer a la de gobernante, lo que certifica con sus actuaciones en política exterior con la enemiga Dinamarca y la aliada España.

De hecho la comedia se abre con cuestiones bélicas de la historia sueca: las famosas victorias militares de Carlos Gustavo sobre Dinamarca, su enemiga natural, y el apresamiento de la princesa danesa Leonor. Y a excepción de esta, con la que finalmente se casará Carlos Gustavo, la conducta de los daneses no es la adecuada: el rey se dispone a liberar a su hija por las armas en vez de negociar, por lo que la reina renuncia a dejarla en libertad voluntariamente como era su intención:

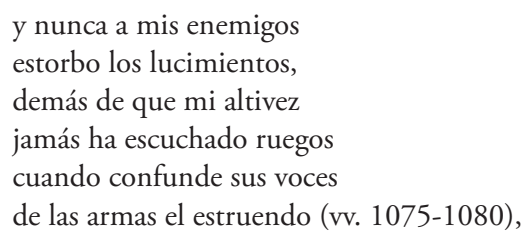

y también el duque, hermano de Leonor, que la pretende por razón de Estado, quedará desacreditado y anulado al final, por haber suplantado al embajador de Dinamarca en la corte sueca, por lo que cuando lo descubre Cristina es objeto tanto de su indulgencia como de su indignación. Es decir, de igual manera que es cercana y clemente se muestra implacable y severa con los enemigos y cuestiones de Estado como recogen las crónicas:

Es tan amigable en sus conversaciones que quien la ve no dijera ser reina [...] Y cuando trata de cosas y oye embajadores de reyes vuelve a cobrar tanta majestad que los más intrépidos tienen miedo ${ }^{29}$.

29. Úrsula de Allendesalazar, La reina Cristina de Suecia, Madrid, Marcial Pons, 2009, p. 212. 
En contraste, la posición con España y su representante Pimentel desde el inicio es de afecto y admiración, atenciones, distinciones y favores: accederá a pernoctar en casa del español; en las fiestas venatorias y de máscaras que organiza la corte la reina elegirá ser su pareja; cierra o abre las escenas con él (la primera aparición de Pimentel es de la mano de la reina, «Sale don Antonio Pimentel a la española, trayendo de la mano a la reina"), lo distingue con la Orden de la Amaranta:

$\begin{array}{ll} & \text { Pero antes quiero deciros } \\ & \text { una merced que os he hecho. } \\ \text { Don Antonio } & \text { De tantas como recibo } \\ & \text { no basto a estar obligado, } \\ \text { ved qué será agradecido. } & \text { Yo cierto orden militar } \\ \text { pienso dejar a los siglos } & \text { que se llame la Amaranta, } \\ & \text { y de ella ser determino } \\ & \text { yo misma la gran maestre } \\ \text { por ilustrar sus principios; } & \text { y así de esta insignia quiero } \\ \text { por caballero elegiros (vv. 1866-1878), }\end{array}$

y será Pimentel quien lea una carta de puño y letra de la reina que dirige a don Luis de Haro, transcripción de la que efectivamente le envió Cristina en 1655 cuyo texto coincide prácticamente con el original (vv. 2707-2712); y con él en un aparte tratará asuntos de Estado en apenas cincuenta versos, en los que implícitamente Pimentel alude a su abdicación y conversión:

$$
\begin{aligned}
& \text { ¿quién dirá } \\
& \text { que, cuando tratáis conmigo } \\
& \text { unas materias tan altas } \\
& \text { y de tan graves motivos } \\
& \text { que la Europa aún sin saberlos } \\
& \text { se pasmará al discurrirlos, } \\
& \text { tan hallada en estas fiestas } \\
& \text { estéis y con tan tranquilo } \\
& \text { semblante? (vv. 2019-2027) }
\end{aligned}
$$

Cuestiones que, sin embargo, no volverán a mencionarse hasta el desenlace en que la reina abdica, traspasa el reino a Carlos Gustavo, y premia a cada uno, especialmente al embajador español:

$\begin{array}{ll}\text { Madama } & \text { En Ambers mi residencia } \\ \text { Don Antonio } & \text { Los motivos generosos } \\ & \text { de tanta mudanza hoy muestras, } \\ & \text { otros se sabrán por gloria } \\ & \text { de España y aun de la Iglesia, } \\ & \text { si conseguimos en tanto }\end{array}$


que haya probado la idea quién es quien premia al amor:

o aplauso o perdón merezca. (vv. 3612-3621)

De manera que la reina Cristina se perfila y actúa según la imagen histórica del momento de estas negociaciones, una reina de poder y autoridad reconocidos, en los que sustentará sus propósitos personales, pero también se modela como mujer acicalada, pretendida, ofendida en su vanidad, e incomodada en su orgullo.

En definitiva, María de Molina y Cristina de Suecia son mujeres históricas que constituyen una indudable excepción y por ello permiten crear personajes ejemplares de autoridad y poder en el teatro del Siglo de Oro, si bien en María de Molina prevalece el reino frente a la mujer, mientras que en Cristina de Suecia se impondrá la mujer frente al reino. 